\title{
Design for Enhancing Material Appreciation: An Application on the Palm Tree Midribs
}

\author{
Alaa El Anssary ${ }^{1, a^{*}}$, Nariman G. Lotfi ${ }^{1, b}$ \\ ${ }^{1}$ German University in Cairo, Egypt \\ aalaa.elanssary@guc.edu.eg, bnariman.gamal@guc.edu.eg
}

Keywords: palm tree midribs, material appreciation, emotional design, user perception

\begin{abstract}
Despite academic and professional efforts to extend the uses of palm midribs in production, there is lack of user appreciation or interest in the end product. Most studies focus on the palm technical characteristics to compete with standard wood, disregarding emotional factors that are essential in product promotion. Recent applications eliminate material naturalness, creating artificial substitutes and confusing users who prefer material genuineness. The study aims to analyze perceptions that could lead to the integration of palm midribs into local products by demonstrating visual and tactile attributes. The research highlights designer involvement in product development. Due to the material nature, engineers and designers must collaborate to develop products technically and emotionally. Two experimental design methods were conducted with participants from each group concerned with developing the material. Participants evaluated the material surface from their perspectives in terms of visual and composition. Results revealed that diverse feelings of tactile attributes create sentiments and intellectual curiosities, evoking value and appreciation for the material. Although both groups perceive and communicate differently, they have similar objectives: successful material implementation. In order to enhance designer-engineer cooperation, a multidisciplinary platform was developed enabling material features to be integrated in product development. By focusing on palm by-product naturalness designers and engineers can create meaningful and delightful user experiences.
\end{abstract}

\section{Introduction}

The byproducts from date palm tree (Phoenix dactylifera) are natural materials available vastly in Egypt. Despite that they have been around for centuries, researchers are only starting to approach their full potential as materials for manufacturing. As imported wood prices are increasing, Egyptian manufacturers are eager to find a substitute material with similar performance and characteristics and lesser cost. One particular part of the date palm tree, the midrib, is a renewable material source, allowing its use in sustainable methods and as consequence reducing carbon emissions in the local environment. Most of the previous researchers and applications have approached the palm midrib material from an engineering point of view, with a particular focus in the material technical characteristics such as its strength and flexibility [1]. Furthermore, end users may not trust in products made from midrib material as it is not yet familiar or widely appearing. Therefore, there is a lack of existing designed products as references focusing on intangible characteristics such as the emotional and tactile attributes of the material. Positively, we assume that the sensorial properties of the midrib material can capture the imagination of engineers and designers alike to develop trendy products that make a strong impact on purchaser decision.

Essentially, palm midrib is considered a waste which is burned similar to rice ash. Updated manufacturing techniques transform midribs into compressible strips to produce block boards 
and other marketable furniture items. El-Mously, a well-known researcher in this field, is working on rediscovering different uses of Palm Trees' secondary products as renewable resources to satisfy national and international demands for specific applications [2]. He confirmed in different publications that midrib material's modulus of rupture (MOR) and tensile strength is similar to pine wood. The midrib material's outer layer offers a specific tensile strength of $196\left(\mathrm{~N} / \mathrm{mm}^{2}\right) /\left(\mathrm{g} / \mathrm{c} \mathrm{m}^{3}\right)$ to $142\left(\mathrm{~N} / \mathrm{m} \mathrm{m}^{2}\right) /\left(\mathrm{g} / \mathrm{c} \mathrm{m}^{3}\right)$ of the European Reed Pine, making it an alternative to imported timber [3]. Another remarkable effort made by Egyptian engineers and craftsmen was a series of handmade furniture pieces developed from palm fronds boards created specifically to present innovative structural properties. They successfully utilized the results of the engineering research to extend the potential of this raw material and explore a new dimension in artisan capability. For example, furniture pieces shown in Fig. 1, developed by start-ups such as Jereed and Jozour [4] are interesting applications not just in terms of the form structure but also regarding the design process in which design and material properties can be compromised together [5].

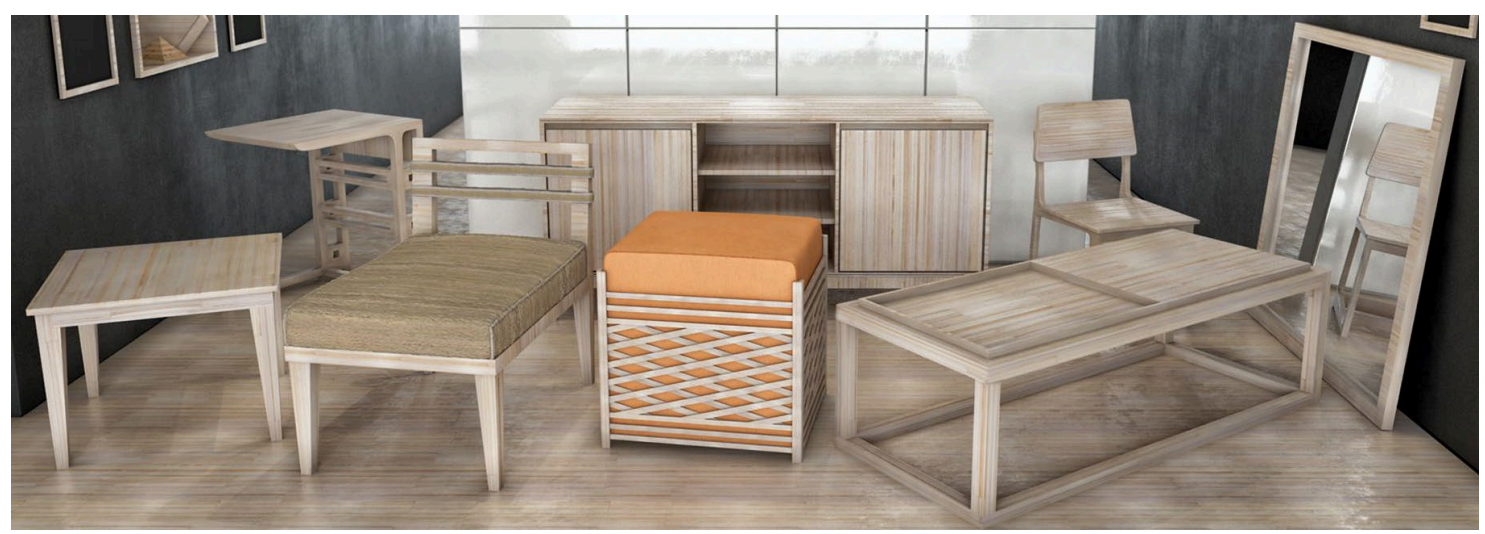

Fig. 1: Jereed Furniture Products made from Palm Midribs [4].

This is an innovative and integrative point of view, since generally designers perceive materials and generate judgments based on sensorial properties resulting from appreciation of the product form. On the other hand, as engineers, mechanical and environmental resistance properties are the main focus. Consequently, there is a huge informational and perceptual gap between the two fields explaining why tensions and clashes between the two disciplines evolve.

Therefore, this paper aims at studying the interpretations of designers and engineers towards the palm tree midrib in order to develop a strategic platform that enables better communication and understanding between both academic and professional views. By doing so, improved products and designs using the newly developed material can be introduced to the Egyptian and international market successfully.

\section{Multi-dimensions of possibilities offered by palm midribs}

Palm midribs have numerous possibilities of applications taking in account their sustainable, physical, mechanical, aesthetic and symbolic properties. Previous tests carried out on the midrib show that it has pronounced physical and mechanical properties. The midrib enhanced strength is comparable to Beech and Spruce wood. According to a research conducted at Munich University, it was found that the exterior layer of the midrib has a tensile strength 4 times superior in comparison to steel. The extraction process of the material involves trimming, cutting then compressing it using a storage room to control oxygen, carbon dioxide, and nitrogen levels. 
Therefore, the materials increased qualities and uses are due to the midrib's radical transformation from a living material to hardwood [5].

Date palm midribs can be employed to produce wood-cement panels (WCPs). The results showed that the WCPs from C. erectus maintained higher stability in water than those produced from P. dactylifera. The mechanical properties of the WCPs made from the date palm midribs exceeded the minimum requirements; the dimensional stability characteristics of the panels were also lower than the maximum limits of particleboard standards as presented in Table 1 [6].

Table 1. Values of the mechanicals and dimensional properties of WCPs from the date palm midribs and buttonwood.

\begin{tabular}{|c|c|c|c|c|c|c|c|c|}
\hline & \multicolumn{5}{|c|}{ Mechanical properties } & \multicolumn{3}{|c|}{ Dimensional stability (\%) } \\
\hline & MC & Density $^{+}$ & MOR & IB & JHN & Water & Thickness & Linear \\
\hline Wood species & $(\%)$ & $\left(\right.$ kg.m $\left.{ }^{-3}\right)$ & (MPa) & (MPa) & (N) & uptake & swelling & expansion \\
\hline$P$. dactylifera & $8.45^{\wedge}$ & $1250^{\wedge}$ & $11.20^{\wedge}$ & $1.76^{\wedge}$ & $5795^{\wedge}$ & $23.03^{\Lambda}$ & $1.34^{\Lambda}$ & $0.50^{A}$ \\
\hline C. erectus & $8.65^{\wedge}$ & $1255^{\wedge}$ & $11.75^{\mathrm{A}}$ & $1.74^{\mathrm{A}}$ & $5371^{\mathrm{B}}$ & $19.34^{\mathrm{B}}$ & $0.57^{\mathrm{B}}$ & $0.34^{\mathrm{B}}$ \\
\hline Requirement & - & 1200 & 9.00 & 0.45 & 2222 & - & Max 8.0 & $=$ \\
\hline
\end{tabular}

Characteristics such as high strength and elasticity can inspire product designers to create a wide range of new applications. Another advantage of using palm midribs is in the reduction of carbon emissions by the avoiding of its burning. This material is extracted from the palm tree fronds, in which 10 to 26 leaves grow every year. Without using, it constitutes a waste of approximately 965 tons annually in the Middle East [5]. On the other hand, because the frond renews itself it is a consistent local material resource, reducing the cost to import wood and reducing carbon emissions. It can also save cutting down trees and, in this way, reduce deforestations. Therefore, full utilization of palm midribs supports local manufacturers substituting imported woods and benefits the ecosystems by relieving pressure on forests [2]. Thus, employing palm midribs is possible to create wealth and awareness to the Egyptian market, diminishing costs related to wood importation and the repercussions of exhausting nonrenewable resources on the environment.

The date palm midribs were successfully used in different furniture applications such as parquet boards, doors, and "Mashrabia" handicrafts, a design similar to architectural window elements commonly used in Arabic residences for privacy [3], [5]. These applications indicate that characteristics palm midribs present stability and durability to be employed as a skeleton for structures as well as laminated materials. Customers are increasingly looking for sensorial properties and emotional experiences while interacting with products [7]. The sensorial properties of the materials should be applied to create meaningful perceptions and associations that attract the user. The surface of palm midribs gives a unique feeling and impression emphasizing tactile qualities. Special aesthetical advantages of the palm midribs such as natural warmness, calming, kindness and urbanity are crucial for designers to create products that evoke powerful emotional experiences.

Thus, this paper focuses on the tangible and intangible characteristics of palm midribs in order to assist in representing a new market value. These unique tangible material characteristics are based on sensory aspects and can be categorized into visual and tactile attributes. The visual attributes of the material are according to the placement and orientation of the midrib strands, either horizontally or vertically. The horizontal placement creates the image of different shades of wood lines across the product surface. The vertical formation creates a mosaic looking effect 
that appears similar to marble or stone. The vertical placement shows the square base of the strands and highlights the different wood shades. The tactile attributes are the rough texture of the material. If the strands are placed horizontally without treatment the material is raw with a slightly rough texture. Vertically, the square bases of the strands are normally sanded giving the material a smoother surface.

\section{Experimental methods: Material evaluation from different perspectives}

New ideas evolve out of the tension between different disciplines. In the product development process, designers and engineers face a perceptual gap that is driven from their different educational backgrounds [8]. It is important for both professions to adopt a more explorative approach to each other that may help in providing the platform for unconventional innovation. The interpretation of a material like palm midribs from different aspects can give deep insights inherent within the user experience. The experimental methods carried out in this research have a qualitative nature and were developed to evaluate and gather information on the following:

- Process of working in a multidisciplinary team to identify the issues/ conflicts;

- Participants' perceptions and opinions on the materials;

- Similarities and differences between the professional perspectives;

- Complications and difficulties working together.

The method of research was a semi-structured interview conducted on a sample of experts according to their backgrounds, knowledge, and experiences in working with the midrib material. Participants were both males and females, ranging from 24-34 years of age, originating from Egypt. The total sample consisted of 13 participants including:

- 7 designers concerned with palm midrib material and working in the furniture design field.

- Co-founder of Jereed, a start-up that develops products using the midrib material. The participant was from an engineering and machinery background.

- CEO and engineer from Jozour, a start-up that also develops home accessories using midrib material.

- Business developer at Jozour start-up.

- 2 engineers concerned with material sciences from the German University in Cairo.

The qualitative research methods conducted were:

1. Semantic Differential Scale

The Semantic Differential Scale was developed by Osgood in 1957 [9] to test a users' perception towards a product. This method helps to get an idea of how users perceive an object to further develop or modify it. It employs a set of bipolar adjectives to describe the product or, in this case, the material. Participants are then asked to select on a Likert scale the relevant term that shows how they perceive that object. For example, whether they perceive a product to be safe or dangerous, attractive or ugly, etc. [10]. The keywords used in a scale are derived from the human senses including visual, tactile, haptic, auditory, gustatory, and kinesthetic so that a clear idea of their perceptions can be analyzed. This method was used in this study to identify the similarities and differences between the perceptions of designers and engineers. Fig. 2 shows the four midrib board samples materials produced by different techniques given to the participants. They were asked to rate the sample according to several sensory keywords. The DPLM wood boarding samples were:

A. Midribs arranged horizontally on longitudinal and tangential surface 
B. Midribs arranged vertically on vertical and cross section view

C. DPLM board with veneer coating

D. DPLM board as sandwich panel

Results were plotted in a map, as shown in Fig. 3, and analyzed according to the keywords in common between designers and engineers as well as the differences.

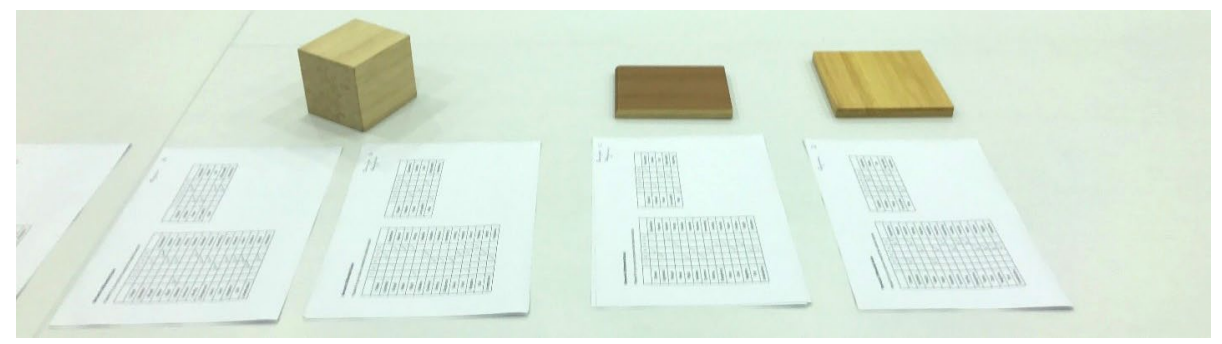

Fig. 2: Four samples of different midrib board techniques shown to the participants. From left to right, the samples were DPLM on longitudinal and tangential surface (midribs arranged horizontally), DPLM on vertical and cross section view (midribs arranged vertically), DPLM with veneer coating, and DPLM board as a sandwich panel [1].

2. Focus-group session

A focus group was conducted to address the process of working together and conflicts that would rise between each profession. The sample was focused because it consisted of participants who all worked on developing products using the palm tree midrib material. The group consisted of four participants; two designers and two engineers. Their background formation was their level of experience working with the midrib material. The designers were furniture designers who previously developed midrib products and the engineers were co-founders of Jozour start-up. The participants were asked how they perceived the material, the communication process, and their knowledge about the market through a semi-structured interview. They were asked what was successful with the process of working with another discipline and what they would do to develop it.

\section{Findings: The perceptual gap between two disciplines}

According to the Semantic Differential Scale, a clear gap was apparent between the engineers and designers regarding how they perceived the samples in respect to strength, quality, and cost. Fig. 3 shows the mapping of the perceived keywords where it indicates the clear gaps/ skips related to the material and the similarities or agreements are shown when the lines are close to each other. The scale highlighted the words related technically to the material properties were perceived differently. For example, engineers would perceive the material as synthetic, precious, and expensive whereas designers would see it as natural and common. This indicates that due to the expertise and experience of the engineers with the material they can perceive its properties technically in a more realistic sense. By analyzing where the disagreements and agreements are, we can begin to gain an understanding of the similarities and differences between the two disciplines.

The analysis of the results in Fig. 3 showed that there were some differences between the two professions, meanwhile Fig. 4 describes the keywords that designers and engineers individually perceived. The common perceptions between both professions (warm, high quality, friendly, strong, bright, and positive) were highlighted and analyzed as the basis for the platform development. This indicated that participants of both professions perceive the material according 
to those keywords. It is also important to underline that the term "high quality" was agreed on by the participants in relation to two different samples which were: B. midribs arranged horizontally and D. DPLM board as sandwich panel. This can be due to their experiences with the material or according to their emotions towards the samples.

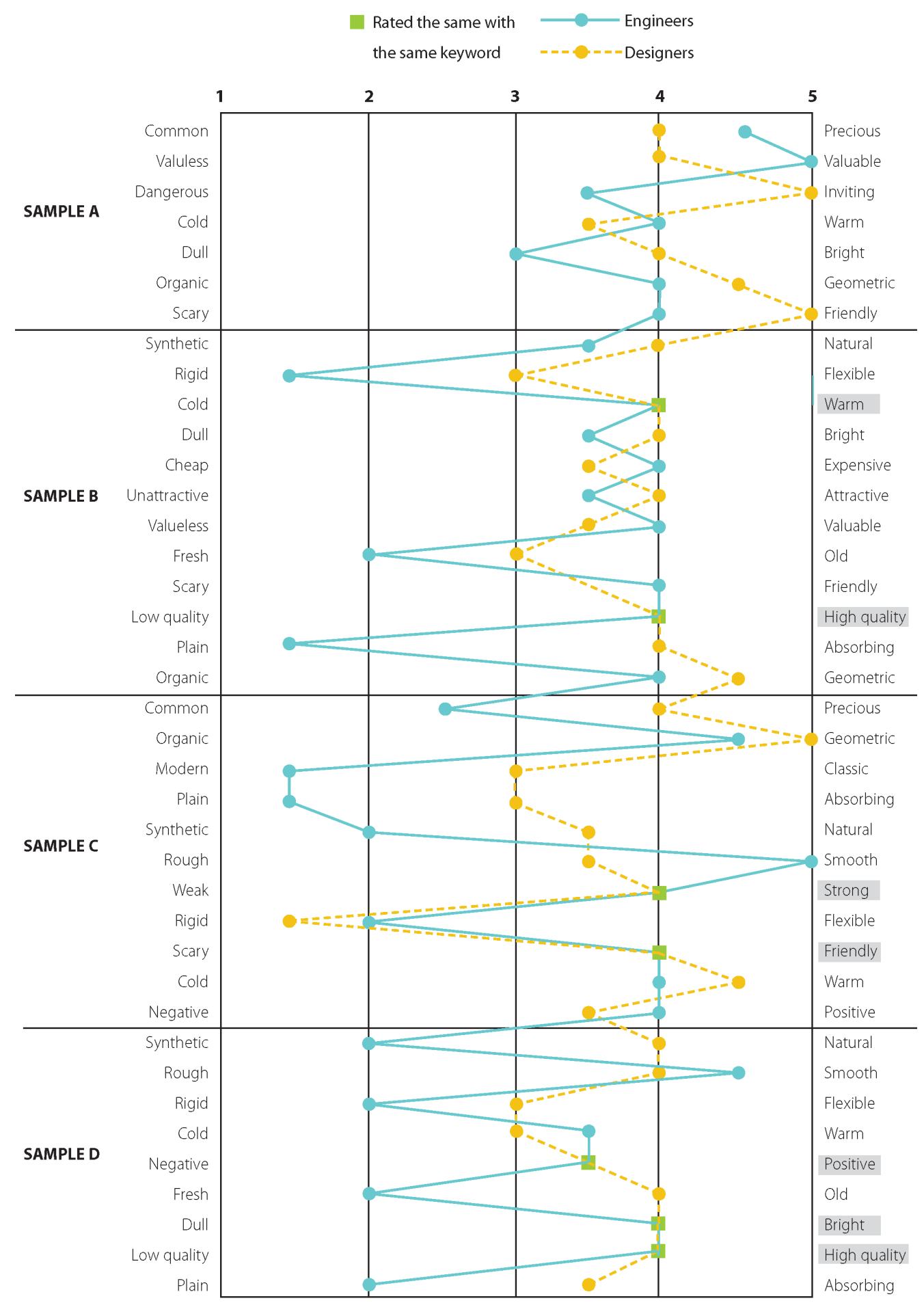

Fig. 3: Semantic Differential Scale analysis of similar keywords employed by engineers and designers. The map shows the words that were in common and the ones that were different. 

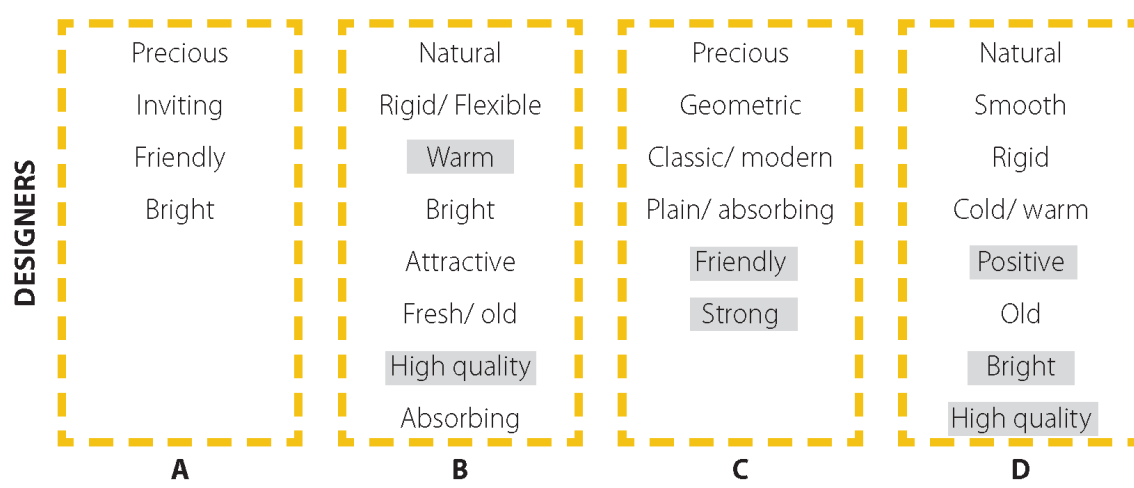

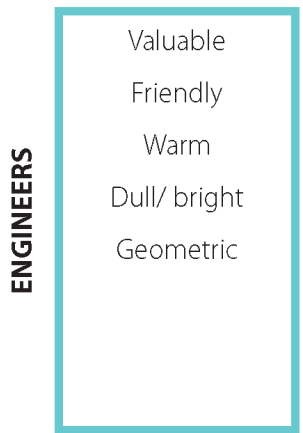

A

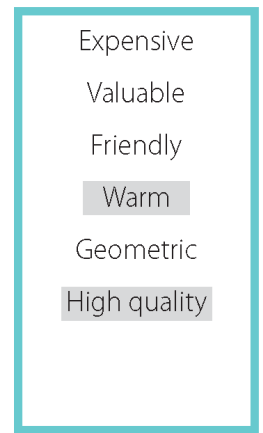

B

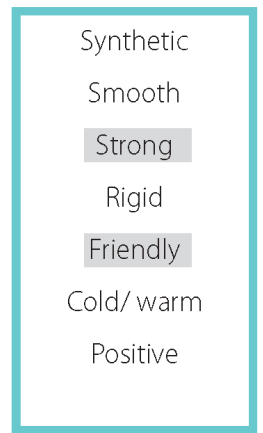

C

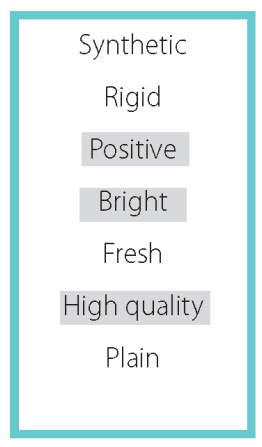

D

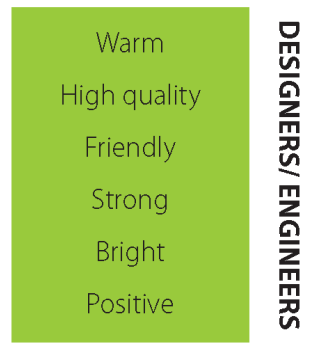

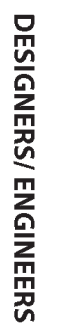

Fig. 4: Keywords perceived by designers and engineers. The highlighted words were the ones found to be in common between participants of the two professions.

When asked in the focus group if they believe to perceive the materials differently a designer stated that although both designers and engineers focus on the function, they do not always perceive the finishing in the same way. This statement was also proven correct using the scale presented in Fig. 3 because there were clear disagreements on the finishing of a material in regard if it was (or not) smooth or modern. Because of the involvement of engineers with material producing they realized the material differently to the designers and the market because they were concerned with sustainability promoting. However, from their business experience, they found that the local market was not interested in this aspect. It is more interested on new functions such as product customizing; adding new colors, illustrations or patterns to useful products.

Designers found the challenges in communication were due to a lack of flexibility with testing or changing the material as well as limited appreciation towards the value of the design. The design is able to transform the product which is an understanding that is difficult to communicate to the manufacturer. Engineers found that highlighting specific terminologies and keywords, which are important to designers, is generally missing in a multidisciplinary project process. They felt that these needs should to be clearly delivered in two or three sessions prior to working on a project so that the process moves forward smoothly without miscommunication.

The design discipline focuses on the emotional elements inherent within a user's experience. Therefore, the technical information about a material such as the midrib should be provided in a form that is matched with people's needs and triggers the designer's sensibility. By developing everyday products for users to get familiar and evoke the market curiosity the midrib material could become accepted. Designers believe that material characteristics and limitations need to be clearly communicated and shown visually by engineers before beginning a project. When 
marketing and selling the products, its value must be shown in the pricing of it to indicate the quality of the material and the design.

Design understanding for engineers should be enhanced to reinforce feasibility of new palm midrib applications. Engineers should work in developing ideas in an integrative way with the designers early in a project. Based on the experience of the engineers, it was found that the market demand was for a unique, well-designed product. However, in order to create a smoother workflow, designers must reach an understanding regarding the material properties and manufacturing methods. They must also communicate their ideas technically in a logical manner for the engineers to understand their idea interpretation.

\section{Multidisciplinary Platform Description: a perceptual synthesis of midrib properties}

The multidisciplinary platform is a proposal developed according to the synthesis of three project elements which consists of: using the emotional and symbolic characteristics of the palm tree midribs, developing the business strategy, and incorporating engineering aspects. In the frame of these three areas, market research is the key factor that aims to understand the needs of customers to discover the market opportunity. Market research is the core of any business strategy that, in the case of products made of palm tree midribs, helps both designers and engineers to diffuse a new meaning to the value of the midrib material from different angles. However, according to Fig. 5, the main objective of the suggested platform is to outline the common areas of interest in each field. This implies that, for designers, the properties of the material related to the tangible sensory characteristics including visual tactile, haptic, auditory, gustatory, and kinesthetic perception or the intangible characteristics are mainly focused to evoke a certain emotion that cannot be communicated or described.

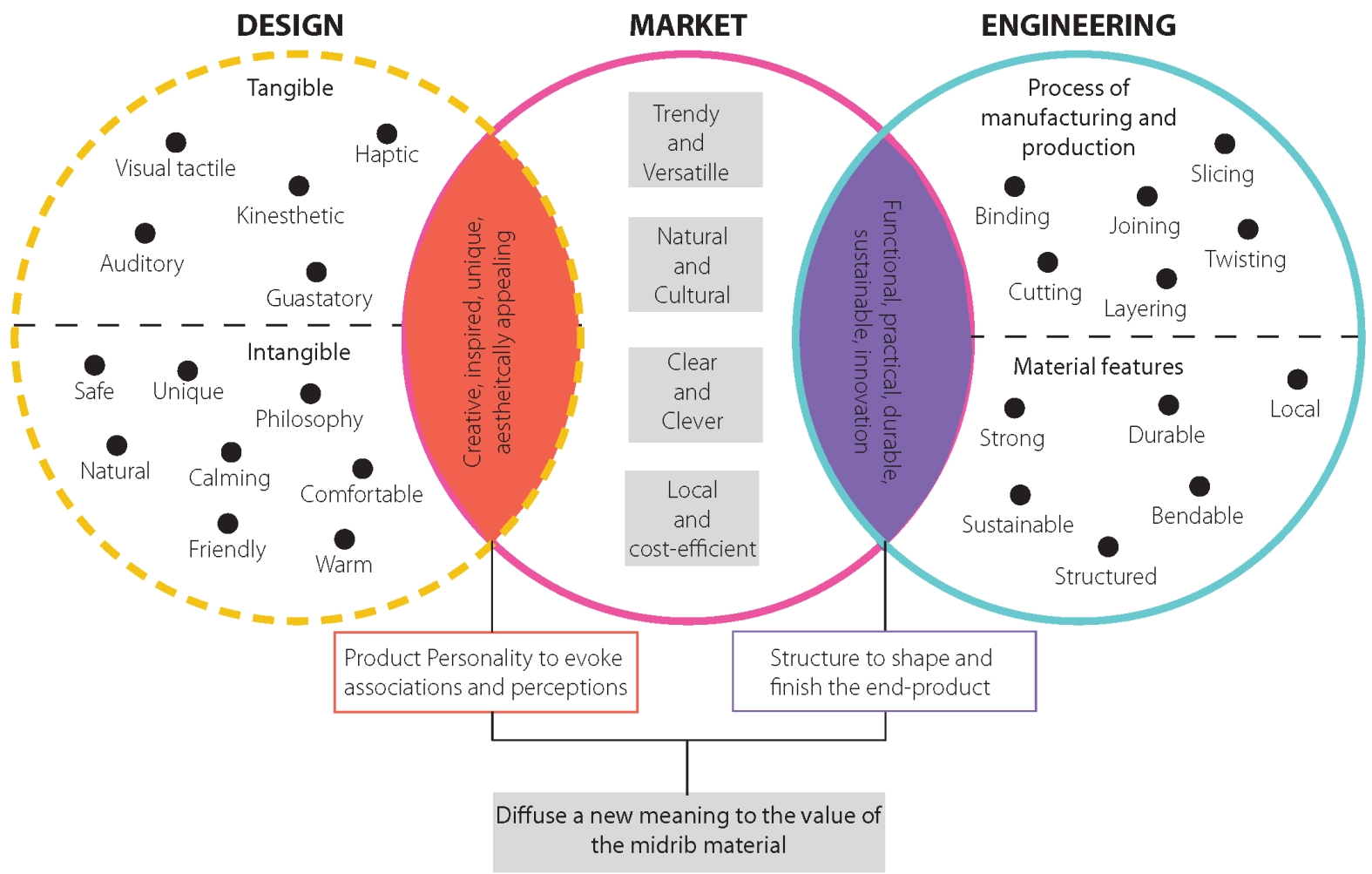

Fig. 5: Multidisciplinary Platform to highlight the main elements of each profession and the four key factors needed by the market. 
The co-designing process is an opportunity to develop new experiences through several applications that allow designers and engineers to maximize the value of product creation. In order to track the integration of design and engineering aspects as a business strategy, the multidisciplinary platform emphasizes four inspiring topics to establish a common ground of interest extracted from the different vocabulary and terminology that continually appear among the concerned disciplines using the palm tree midribs: (1) trendy and versatile; (2) natural and cultural; (3) clear and clever; (4) local and cost-efficient (Fig. 5). These four topics cover the impact of the midrib material (tangible and intangible characteristics) on the user's insights that contain language both sides can understand. In other words, the four topics include different types of knowledge and market demands implying a specialized set of properties that should appeal to the senses of users.

Through a specific set of features of midribs, two overlapping roles will represent the way by which the four mentioned topics can be appropriately interpreted. Each role falls to one of the two disciplines:

1. Providing structure to shape and finish the end-product (engineering);

2. Creating product personality that evoke associations and perceptions (design).

This scheme is a perceptual synthesis of properties that can affect more than the direct visual and tactile features of the product. It guides designers and engineers to employ the features of midribs in an unconventional way to evoke feelings of sensory experience related to the user of the product.

\section{Conclusion}

According to the research, it was found that both designers and engineers have the same end goal: to produce new products using the midrib material that can be sold to the market. However, both professions focus on different areas of the process according to their disciplines. Therefore, the platform shares the current information that is accessed by both disciplines to aid in the product development process. By developing a strategy that enables a successful multidisciplinary collaboration the value of the midrib material will be enhanced. On the other hand, traditional research methods, mainly engineering testing techniques, used to explore the possibilities of applications for such a material have to be developed in collaboration with designers to gather deep insights into the sensorial characteristics of the midrib material. The intangible aspect of midribs will attract a greater market which will enable an economically stable business approach.

The need and demand for an alternative material to the imported wood is increasing rapidly in Egypt. However, the market is still in the phase of being unsure what to expect from this material. It is the role of the designers and engineers to communicate and work together to bring forward a product to the market with this material that fulfills the market gaps; a trendy, functional, affordable, unique, attractive, and durable locally produced product.

\section{Future recommendations}

It is recommended that the study continues testing on a wider scope of users to be implemented onto the market. This will create a greater knowledge of the needs of market to develop a successful multidisciplinary project. The Semantic Differential Scale can be adapted and tested on consumers to get an idea of their perceptions and to analyze if they share the same perceptions as the designers and the engineers. The developed platform needs to be tested in the form of a case study with several designers and engineers to find out more information on the two professions and how to create successful collaboration for the future. 


\section{References}

[1] CrossLink Technoqlogies. Preliminary Technical Report. Vancouver: U.S. (2016).

[2] H. El-Mously, Innovating green products as a mean to alleviate poverty in Upper Egypt, Ain Shams Eng Journal (2017) 3-7. https://doi.org/10.1016/j.asej.2017.02.001

[3] H. El-Mously, The Industrial use of the Date Palm Residues: An Elequent example of Sustainable Development. 11th International Conference on Date Palms, Al Ain, United Arab Emirates (2001) 866-886.

[4] Jereed Furniture Products [Image] (2015), Retrieved December 3, 2018 from https://www.facebook.com/Jereedeco/photos/a.1488347228138145/1488347191471482/?type=1 \&theater.

[5] A. Eldeeb, Recycling Agricultural Waste as a Part of Interior Design and Architecture History in Egypt, The Academic Research Community Publication (2017) 2-6. https://doi.org/10.21625/archive.v1i1.116

[6] R.A. Nasser, Influence of board density and wood/cement ratio on the properties of woodcement composite panels made from date palm fronds and tree prunings of Buttonwood. Alexandria Sci. Exchange J. 35-2 (2014) 133-145. https://doi.org/10.21608/asejaiqjsae.2014.2588

[7] R. Jensen, The Dream Society. The coming Shift from Information to Imagination, McGrawHill Book Company, 1999.

[8] J. Cagan, C. Vogel, Creating Breakthrough Products, Financial Times Prentice Hall, Upper Saddle River, New Jersey, 2002.

[9] C.E. Osgood, C.J. Suci, P.H. Tannenbaum, The Measurement of Meaning. University of Illinois Press, Urbana (1957) 76-124.

[10] S.H. Hsu, M.C. Chuang, C. C. Chang. A semantic differential study of designers' and users' product form perception. International Journal of Industrial Ergonomics. 25 (2000) 375-391. https://doi.org/10.1016/s0169-8141(99)00026-8 